\title{
La cultura como conquista: Naturaleza y condición en la definición de la identidad humana
}

\section{Culture as Conquest: Nature and Condition in the Definition of Human Identity}

\author{
Luis Díaz Viana \\ Grupo de Investigación Antropología Comparada de España y América ACEA. \\ Centro de Ciencias Humanas y Sociales. CSIC. Madrid
}

\section{RESUMEN}

En los últimos tiempos, el viejo debate en torno a naturaleza y cultura, que es una discusión - finalmente- sobre la definición de lo humano, ha adquirido las formas extremas de una pugna (tanto filosófica como a pie de calle) entre "animalistas" e "hiperhumanistas"; entre quienes pretenderían — humanizando a los animales en materias como las de sus derechos- propiciar, según sus opositores, una cierta "animalización del hombre" y quienes, desde las perspectivas contrarias, estarían agrandando la brecha entre los humanos y los animales para justificar —así- el maltrato y sacrificio de estos últimos en nombre de la tradición y la cultura. Este trabajo viene a recordar que los abusos reduccionistas del "sociobiologismo vulgar", que ahora se presentan a veces como novedosos, ya fueron contestados suficientemente desde la antropología en el pasado; y propone, tanto frente a ellos como ante el "hiper-humanismo misticista", la reivindicación de la cultura como conquista de nuestra especie por la que llegamos a ser humanos, recuperando - precisamente de este modo- el programa de aquella antropología que promovía, desde el conocimiento de la diversidad cultural, una positiva "humanización" del mundo.

Palabras clave: Salvajismo; Civilización; Humanización; Deshumanización; Cultura; Lenguaje; Narración.

\section{SUMMARY}

In the past few years, the old debate about nature and culture, a debate which is - ultimately - one on the definition of the 'human', has acquired the form of a controversy (both philosophical and everyday) between "animalists" and "hyper-humanists"; between those who would claim a certain "animalisation of humankind" — humanising 
animals on issues such as rights - and those who, on the contrary, make attempts at widening the division between humans and animals to justify practices of mistreatment and sacrifice of the latter in the name of tradition and culture. This paper mantains that reductionist abuses of "vulgar sociobiology", now at times presented as innovative, were adequately questioned by anthropologists in the past; and proposes, both against these views and as opposed to what has been called "mysticist hyperhumanism" by some authors, a reivindication of culture as a conquest of our species leading us to humanity, retrieving in this way the program of that anthropology which, coming from the acknowledgement of cultural diversity, promoted a positive "humanization" of the world.

Key Words: Savagery; Civilization; Humanization; De-Humanization; Culture; Language; Narration.

El debate sobre naturaleza y cultura parece partir del supuesto de que una y otra cosa son distintas y hasta contrarias. Sin embargo, se trata de una discusión —desde luego mantenida por humanos y no por otros animales - que tiene a lo humano como centro de su reflexión. Y es precisamente la misma realidad humana la que más desafía esa separación o dicotomía. Como debate propio de humanos y centrado sobre lo humano que es no suele agotar, de otra parte, todas las derivaciones del problema: si en la naturaleza hay o no cultura u otras formas de cultura parecidas o distintas a la humana y si la cultura tiene que ser algo necesariamente distinto o ajeno a la naturaleza. Por supuesto que, además, para afrontar esos otros flancos del debate habríamos de ponernos previamente de acuerdo en las definiciones de cultura y naturaleza que vayan a manejarse o —más alláen el propio concepto de lo bumano.

$\mathrm{Y}$ es ahí donde radica el fondo de la cuestión, pues quienes desde distintas disciplinas, pero muy particularmente la filosofía, se colocan o alinean a uno y otro lado de la discusión parecen dar por supuesto que asumir que lo humano es una naturaleza niega de alguna manera al hombre y su humanidad o que aceptar que lo humano es fundamentalmente cultura negaría lo natural en él. Buena muestra de ello, en nuestro ámbito, serían las opiniones y libros cruzados recientemente entre Mosterín y Gómez Pin con sendas obras aparecidas en el mismo año y en la misma editorial: La naturaleza bumana (Mosterín 2006) y Entre lobos y autómatas: La causa del hombre (Gómez Pin 2006). Como las palabras son importantes en todo debate, pero muy especialmente en éste, convendrá aclarar que aquí va a utilizarse el término humano para designar todo aquello que consideramos propio de los seres que responden a ese calificativo: hablar, pensar, transmitirse conocimientos socialmente y, lo que no es menos relevante, compartir un sistema simbólico específico... Distinguiendo, además, ese conjunto de características que suelen identificarse con la cultura de la mera 
capacidad natural para adquirirlas que los nacidos hombre/mujer poseen. Se pensará que una distinción así es innecesaria u ociosa, ya que todos los hombres y mujeres hacen o llegan a hacer tales cosas salvo que ciertos problemas físicos o mentales se lo impidan. Que - como la antropología no ha dejado de recordarnos- lo que caracteriza universalmente a los miembros de nuestra especie es vivir, pensar y hablar de acuerdo con una cultura y que esas culturas sean diversas entre sí.

$\mathrm{Y}$ esto es generalmente cierto, pero hay algunas excepciones: seres que habiendo nacido hombre/mujer no adquieren las características de lo bumano más que parcialmente porque no llegaron a tener el contacto social necesario para su aprendizaje cultural o fueron tempranamente privados de éste. E incluso aparecieron ante los ojos de sus congéneres mostrando las formas de comunicación y comportamiento no humanos consustanciales a los animales que les habrían adoptado o con los que simplemente habrían convivido.

\section{Entre lo salvaje y lo Civilizado: la falacia Del "HOMBre natural"}

Herodoto habla de un rey egipcio que, deseando poner en claro la lengua materna de la humanidad, hizo que se aislara a algunos niños de los de su especie, teniendo sólo cabras por compañía y sostenimiento. Cuando los niños se hicieron mayores y fueron visitados gritaban la palabra "beckos" o, sustrayendo el final que el sensible y normalizador griego no podía omitir para nada que pasara por sus labios, más probablemente "beck". Entonces el rey envió gentes a todos los países para ver en qué tierra significaba algo este vocablo. Supo que en la lengua frigia significaba pan y, suponiendo que los niños gritaban pidiendo comida, sacó la conclusión de que hablaban frigio al pronunciar su lenguaje humano "natural" y que, por tanto, esta lengua debía ser la original de la humanidad (Alfred L. Kroeber [1917], en Kahn 1975: 55).

Las narraciones sobre "niños salvajes" o feral children - término acorde con el homo feral de Linneo- se nutren de la leyenda o la originan, pero son numerosos los casos documentados históricamente (Malson 1965) y no faltan nuevos ejemplos que siguen apareciendo en la actualidad.

Estas historias causaron pronto el interés de filósofos, psicólogos, antropólogos o educadores, pero — sin embargo- parecen incomodar a quienes gustan de hablar sobre la naturaleza humana en clave socio-biológica, pues generalmente ni los mencionan. Tampoco puede sorprender que los autores de las obras creadas desde esa perspectiva, según la cual la naturaleza y condición humanas serían algo enteramente determinado por nuestro genoma, rehuyan utilizar referencias antropológicas y actúen como si la cultura o la historia fueran aspectos contingentes, pero no inmanentes de 
la especie: todo lo que conviene y se precisa saber de ella, lo que no cambia ni ha sufrido alteraciones en millones de años, estaría en nuestro DNA.

Lo humano, no obstante, desde las aportaciones de la antropología, aparece más como una condición que como una naturaleza o — si se prefierecomo una combinación de ambas, y de ahí la pertinencia de hablar de lo bumano en cuanto a una cualidad no necesariamente equivalente a ser un bomínido bípedo, hombre o mujer. Una cualidad o condición que llevó y lleva tiempo conseguir, de modo que el que se esté programado para alcanzarla no garantiza que siempre se realice. Pues no cabe duda de que los "niños salvajes" eran o son morfológica y genéticamente como nosotros, pero casi ninguno de ellos llegó a desarrollarse del todo como bumano. No se integraron por entero socialmente ni lograron una competencia lingüística similar a la del resto de los humanos, quizá porque en el periodo durante el que éstos adquieren el lenguaje se encontraban aislados de la sociedad o - supuestamente- aprendiendo a imitar a sus primeros cuidadores, ya se tratara de lobos, osos o gacelas. Hay cierta controversia en este sentido sobre si los niños salvajes que no llegan a hablar pudieran padecer algún trastorno - como el autismo- que determinara ese aislamiento. De cualquier modo, la realidad es que, como ha sucedido con el resto de primates actuales que parecían susceptibles de ser humanizados, todas las experiencias y esfuerzos por humanizarlos fracasaron, salvo en algún caso en que el "niño fiera" podría haber aprendido el lenguaje con anterioridad a pasar por su etapa de "asilvestramiento". Los datos que se conocen al respecto son tozudos y desalentadores como recuerda Lévi-Strauss, ya que los niños asalvajados nunca hablaron ni los monos tampoco: "Las investigaciones realizadas desde hace unos treinta años con monos superiores son particularmente decepcionantes" en este sentido; y es más, "la vida social de los monos no se presta a la formulación de norma alguna” (Lévi-Strauss 1991: 38-39).

Algo parecido ocurre con lobos y perros, que no se diferencian genéticamente en nada y, de hecho, pueden volver a cruzarse entre sí y generar prole, como miembros de la misma especie que son. Pero mientras que los perros a menudo vuelven a "asilvestrarse", olvidando los ladridos a través de los cuales se relacionan con nosotros y tornan sólo a aullar, los lobos de ahora no llegan a convertirse en "perros plenos" ni — por ello- ladrarán nunca. Hubo un ancestro común que eligió ser perro y lo consiguió enteramente, pero sus descendientes lobunos actuales no se dejan domesticar más que de manera penosa y parcial.

Con el ancestro de los humanos pudo suceder un proceso semejante. Un primate, en algún momento, escogió el camino que llevaba a la humanización. Sin embargo, todos los candidatos a supuestos eslabones perdidos de esa trayectoria que los paleontólogos han ido proponiendo hasta el 
momento presentan algún fallo o aspecto discutible. En realidad, su presunta humanidad depende en todos los casos de la hipótesis de que llegaron a ser humanos en nosotros pero no hay ninguna prueba contundente de que fuera así, porque faltan demasiadas piezas de ese proceso. Y tal supuesta correspondencia es puesta en entredicho hasta por autores nada sospechosos de antievolucionismo: "A los paleoantropólogos les hace ilusión pensar que los restos fósiles que se encuentran son los de nuestros ancestros, y también lo pensaron los que excavaban Atapuerca" (Mosterín 2006: 131). Los descubridores de tales antecesores nuestros suelen tirarse los trastos cada vez que aparece un nuevo cráneo, mandíbula o trozo de algún hueso no tanto por la discusión de si eran humanos — tal como hoy se entiende-, que evidentemente no lo eran, sino acerca de la suposición de que los restos que ellos han encontrado pudieran haber llegado a ser el humano que conocemos. A propósito de si — por ejemplo- eran bípedos o no, pero - sobre todo- si podían hablar, si ya efectuaban rituales funerarios...

Imaginemos, por un momento, para comprender lo arriesgado de tales suposiciones, que los paleontólogos del futuro sólo encontraran como reliquia de nuestra época —en un perfecto estado de conservación- los restos de uno de estos niños asilvestrados, con su vello hirsuto, sus largas uñas retorcidas, sus dientes desgastados por comer raíces y las callosidades propias en sus extremidades de haberse movido durante años sobre sus manos y pies o — como se dice vulgarmente— "a cuatro patas". Podría deducirse que se trataba de una especie de hábitos simiescos que, sin embargo, poseía ya todas las cualidades que hacen humanos a los humanos. Pues, mientras no se demuestre lo contrario, todos los niños salvajes que han sido documentados eran, en su origen y en su aspecto externo, anatómicamente normales, hombres y mujeres iguales en todo a nosotros. Y, empero, no andaban erguidos, no resultaban capaces de articular lenguaje hablado alguno (sino que se comunicaban por gestos y gruñidos), ni —que se sepatenían consciencia alguna de la muerte. Estos niños "no humanizados" que fueron encontrados en distintos lugares y épocas, de Víctor de Aveyron en Francia (1800) a las hermanas Amala y Kamala de la India (1920), pasando por el alemán Kaspar Hauser (1828) y otros muchos, nunca se reintegraron plenamente en la sociedad. Sin embargo, siempre quedará cierta duda acerca de si ese estado de aparente salvajismo era la causa de su comportamiento anómalo o - por el contrario- el resultado de otras anomalías no visibles de carácter mental (Lévi-Strauss 1991: 37).

Con todo, ha observado lúcidamente Lèvi-Strauss respecto a esta clase de "niños salvajes" que sería un error considerar que representan al "hombre natural" o pueden ser estudiados como si lo fueran. De hecho, les define como "monstruosidades" porque lo "normal" en seres de sus caracte- 
rísticas es que se hagan "humanos" en la cultura: "Los niños salvajes, sean productos del azar o de la experimentación, pueden ser monstruosidades culturales, pero nunca testigos fieles de un estado anterior" (Lèvi-Strauss 1991: 38). Y el homo feral, que no el hombre primitivo, se ve anómalamente privado de esa posibilidad al ser, por distintas razones, apartado de la sociedad y carecer —en consecuencia - de la ocasión de enculturarse. Pero continúa latente la gran pregunta: ¿cuándo y cómo se produce el sorprendente salto que permitió a los homínidos biológicamente preparados para ser humanos desarrollar una cultura que les llevó a convertirse en tales?

Cobra en este aspecto cierto sentido la afirmación de Sahlins, aparentemente demasiado radical acerca de la importancia de la cultura, cuando en sus críticas a la socio-biología que él denomina "vulgar" — para distinguirla de la "científica" - llega a decir: "La biología es completamente incapaz de especificar las propiedades culturales del comportamiento humano o las variaciones que experimentan éstas de un grupo humano a otro" (1982: 3). E, incluso, se atreve a afirmar: "La biología de la Humanidad ha sido conformada por la cultura, que es considerablemente más antigua que la especie humana tal y como la conocemos" (Sahlins 1982: 25).

La frase resulta tan provocadora que requiere comentario y explicación. Porque sólo puede ser válida si lo que quiere decirse con ella es que la cultura, más allá de la genética, ha sido determinante para hacernos como somos. Y que lo que consideramos bumano sólo llega a serlo y realizarse cabalmente por medio de la cultura. Si la cultura es entendida únicamente como el saber adquirido en el seno de un grupo dado habrá que convenir que otros muchos animales son capaces de transmitirse habilidades y aprendizajes a partir de la experiencia propia o ajena. Pero en esos casos quizá deberíamos hablar de "adiestramientos", más que de cultura en un sentido humano. Porque la cultura es lo que confiere a los humanos su identidad. Y consiste en mucho más que en las variaciones en la forma de sobrevivir que se transmiten según los lugares los miembros de una especie a otros, tal y como han podido ser observadas - por ejemplo- en algunos simios. Lo que no niega el hecho de que "primatólogos y otros especialistas hayan podido suministrarnos pruebas decisivas de la existencia de comportamientos, en algunas especies animales, que sin duda podemos calificar de 'culturales`" (Francesch Díaz 2008: 34). Aspecto que ya había sido tempranamente anticipado por Boas (1964: 166), pero que en nada contradice nuestro aserto: que ciertos animales compartan con los humanos modos de conocimiento aprendido no significa que sean lo que son o cobren su identidad por la cultura. Y los humanos sí. 


\section{ENTRE LO HUMANO Y LO ANIMAL: ¿ERA EN PRINCIPIO EL VERBO?}

El presunto oso que buscan unos cazadores, y es un hombre, aparece en varias leyendas. En España es un episodio importante en la leyenda de Montserrat de Fray Garín. Caído este ermitaño en un grave pecado, el Papa le impone que ha de volverse a su soledad andando como los animales y viviendo de las hierbas del campo, que había de arrancar con los dientes. Cazando en las cercanías el conde Wifredo, sus monteros descubren un animal que parecía un oso, y al final lo acorralan, lo conducen al establo del Conde y lo dejan en palacio, donde el monstruo recibe las caricias de todos. Un día se celebraba el bautizo de un hijo del Conde, padre de Riquilda, por cuya pasión se había perdido el ermitaño, y con asombro de todos habla, diciéndole al que pensaban que era un oso: "Levántate, Fray Garín, que Dios ya te ha perdonado" (García de Diego 1958: 66-67).

Los leones, los lobos, los osos, pueden verse apartados desde cachorros de la compañía de sus congéneres e incluso crecer adiestrados para convertirse temporalmente en mascotas, pero no dejan de ser lo que son ni se convierten en humanos por ello. Las historias sobre "niños salvajes" revelan, por el contrario, que esos cachorros de hombre se comportaban como las "fieras" con las que habían convivido y no pudieron ya llegar jamás a ser humanos. Eran homínidos completos, pero por una serie de circunstancias diversas el proyecto humano quedó truncado en ellos. Y es que ese proyecto no se reduce a adquirir un lenguaje, sino a aprehender una cultura de la que el lenguaje forma parte y no al revés. Al no integrarse tales niños en una cultura humana, al no poder compartirla, el lenguaje se hacía innecesario, porque el lenguaje no es únicamente una forma de comunicarse, no existe sólo en función de la comunicación: es la expresión del conjunto de elementos simbólicos que llamamos cultura y a través del cual adquirimos una visión del mundo y las herramientas para interpretarlo. Puede pensarse que "el habla es natural, mientras que la escritura es artificial, cultural” (Mosterín 2006: 201) y reproducir así el viejo esquema según el cual la naturaleza se opone o es algo distinto de la cultura. Pero el habla no es más ni menos natural o artificial que la escritura y la cultura. Porque de ser totalmente natural naceríamos hablando y no es así. Se precisa un largo periodo de aprendizaje — consistente en varios años - para conocer y llegar a ser mínimamente competentes en un idioma. Y existen distintos grados de competencia en el dominio del mismo. Tenemos la capacidad de hablar, de codificar y decodificar el lenguaje, mas sin embargo, e independientemente de si existen problemas fisiológicos que impidan verbalizarlo, cuando no hallamos el entorno necesario para su desarrollo — que no es otro que el de la cultura- no podemos llegar a expresarnos en palabras. Permaneceremos culturalmente mudos y desnudos como el homo alalus, hombre sin habla, ni animal ni humano o puente entre los dos, que ima- 
ginaran ya algunos sabios decimonónicos como Haeckel o Steinthal (Cf. Agamben 2005: 48-51). No hace falta, en efecto, "ir a la escuela para aprender a hablar" (Mosterín 2006: 201), y sí -generalmente- para instruirse en el conocimiento de la escritura, pero ese proceso por el que los niños aprenden y desarrollan un lenguaje no resulta menos cultural que iniciarse en las primeras letras.

Es difícil discernir si esa necesidad de completarse en la cultura resulta una ventaja o una desventaja del humano respecto al animal. Si se será más o menos feliz viviendo según cada uno de los paradigmas que Agamben ha denominado como "lo abierto" y "lo cerrado" (2005), pero en la búsqueda del conocimiento que no de la felicidad consiste la aventura humana. Y nada puede asegurarnos que sabiendo más sufriremos menos. El humano necesita pensarse y contarse para resituarse en el mundo. Si ello se puede deber a carencias o deficiencias del programa natural e instintivo del ser humano, que le harían abrirse a la cultura, tampoco es posible precisarlo. Pero sí es un hecho que para ser bumano ese ser precisa llenarse de cultura. Quizá más bien en ese abrirse y completarse con lo otro, con lo que no es ni era cuando nace, consista su programa. Puede haber un gen que nos capacite para el aprendizaje de la cultura, pero no un gen de la cultura, pues ésta la adquirimos fuera de nosotros o nunca la adquiriremos.

El hiato, el supuesto vacío entre lo humano y lo animal que señala Agamben (2005: 51) se llena solamente con cultura. Lo natural nos viene dado. La cultura es una conquista. Pero naturaleza y cultura concurren en la evolución de lo humano. Lo natural en el ser humano es llegar a serlo mediante la cultura, y por eso tenía plena razón Lévi-Strauss al apuntar que los niños salvajes son anómalos y todo lo contrario al hombre primitivo o natural, homínidos que no se han traducido en bumanos.

Llegados a este punto, convendrá puntualizar que a menudo se trata y se habla de la cultura como si fuera la sustitución del alma, ese soplo incorpóreo que durante mucho tiempo se pensó era la verdadera distinción entre lo animal y lo humano. Se asume desde esta perspectiva la superioridad del hombre sobre el animal y que, por lo tanto, el hombre es algo más que animal. Pero, sin embargo, el bomínido no nace como totalmente bumano. El humano se hace. Resulta lo natural que así sea. Ninguna clase de chispas divinas (llamemos ahora a éstas razón, inteligencia, lenguaje o cultura) se precisan para que llegue a producirse este proceso. Se da o no se da según un cúmulo de circunstancias. Es probablemente fruto del azar, de aquella suma combinatoria de posibilidades a la que apuntaba Lévi-Strauss, que esa opción de llenar parte de nuestra naturaleza con cultura se haya producido: "La humanidad evoca más bien al jugador cuya suerte está re- 
partida entre varios dados, y que cada vez que los tira, los ve esparcirse por el tapete dando muchos resultados diferentes" (Lévi-Strauss 1993: 64).

Ser bominidos es nuestra naturaleza y ser bumanos una condición que se ha logrado con el tiempo y a la que el hombre/mujer tiene la posibilidad e incluso la libertad de renunciar, deshumanizándose. Si hablamos de lo bumano, estamos hablando tanto de una naturaleza como de una condición y -sobre todo- de qué especial manera se relacionan las dos cosas. Los animales pueden, en ciertos aspectos "humanizarse" —como constantemente nos demuestran los animales que viven bajo la condición de mascotas - y los humanos "animalizarse" al quedar segregados del ámbito de la cultura donde se fragua lo verdaderamente bumano. La frontera no es tan clara.

Resulta curioso, en este sentido, el empeño actual de cifrar toda la diferencia entre el hombre y animal en el lenguaje, de parecida manera a como antiguamente el ánima (que sólo el hombre tendría) separaba uno y otro mundo. No obstante, mientras que conceder la existencia de la cultura a otras especies es muy discutible, si entendemos por cultura la cultura humana tal como antes se ha explicado, deberíamos reconocer que no podemos estar del todo seguros de que la forma de comunicarse de ciertos animales no sea —o se parezca bastante- a un lenguaje en la acepción humana. Es decir, una actividad que sirve para algo más que emitir señales y comunicarse. Sería el caso de los cetáceos, que no por casualidad poseen como el ser humano una parte del cerebro, el neocórtex, donde se supone radica la capacidad de raciocinio o pensamiento y que - por cierto- no tienen los simios conocidos. Los delfines, por ejemplo, desarrollan dos tipos de lenguaje (uno verbal y otro semejante al radar o sonar de los barcos), por lo que se podría decir que son — al menos- bilingües, lo que muchos humanos no llegan a ser. Y pueden aprender, comprender e incluso reproducir — siquiera rudimentariamente- el lenguaje de los humanos, lo que es más de lo que nosotros hemos conseguido respecto a su "lenguaje" a pesar de las muchas investigaciones y experimentos llevados a cabo con ese fin (de los de John C. Lily a los de Gregory Bateson).

Y viene al caso recordar todo ello porque existen en la actualidad iniciativas que pretenden y abogan por que se conceda a los grandes simios derechos propios de los humanos. El motivo principal para que ese cambio radical - presentado como una conquista humanitaria y científica- se produzca tiene como base la semejanza de chimpancés, gorilas y orangutanes con nosotros, lo que no deja de reflejar una visión bastante antropocéntrica de la naturaleza. Se habla, así, en relación con los animales citados y de los derechos que quiere otorgárseles, de una "comunidad de iguales" de la que entrarían a formar parte y en virtud de cuya pertenencia merecerían la 
misma consideración ética y moral que los humanos; a pesar de que —al mismo tiempo- se dice (por ejemplo, en la Declaración de los grandes simios) que se persigue, por primera vez, la inclusión en dicha comunidad de "animales no humanos", es decir, desiguales (http://www.proyecto gransimio.org/declaracion.php).

También se expresa en dicha declaración que "el proyecto 'Gran Simio' aspira a ser un paso más en el proceso de extender la comunidad de los iguales". No obstante, y dado que los grandes simios, hoy por hoy, no lo son para - por ejemplo- defender sus propios derechos dentro de esa comunidad igualitaria, se arbitra que "sus intereses y sus derechos deben ser salvaguardados por guardianes humanos, del mismo modo en que se salvaguardan los derechos de los menores de edad y de los discapacitados mentales de nuestra propia especie". Pero un orangután no es exactamente un niño, ni un discapacitado ni siquiera un bomo feral, pues menos el discapacitado que - no obstante siempre puede paliar en parte sus deficiencias mediante el aprendizaje- los otros pueden o podrían convertirse en humanos por entero. En el niño es cuestión de tiempo y enculturación y, en cuanto al homo feral cabe decir que parece que perdió su ocasión de ser totalmente humano, pero si no puede lograrlo aún (cosa que está por estudiarse), podría haberlo conseguido de vivir entre humanos y no lobos, osos, leopardos o gacelas. Los orangutanes, por el contrario, ni son humanos, ni lo han sido ni lo serán nunca. Esa ínfima porción de su genoma en que no somos iguales debe de haber determinado que un orangután no pueda sumergirse con provecho en las aguas comunes de la cultura, lo que pareciendo insignificante a los ojos de quienes consideran la cultura como cosa muy secundaria y no esencial, resulta — sin embargo- decisivo para llegar o no a ser bumanos.

\section{HumanizaCión Y DESHUMANIZACIÓN: EL FUTURO INCÓMODO}

En la Biblioteca Ambrosiana de Milán se conserva una Biblia judía del siglo XIII que contiene preciosas miniaturas [...] La escena que nos interesa en modo particular es, en todos los sentidos, la última, porque con ella terminan tanto el códice como la historia de la humanidad. Representa el banquete mesiánico de los justos en el último día. A la sombra de árboles paradisíacos, y regocijados por la música de dos intérpretes, los justos, con sus cabezas coronadas, se sientan en una mesa ricamente guarnecida [...] bajo las coronas el miniaturista ha representado a los justos no con semblantes humanos, sino con cabeza inequívocamente animal. No sólo volvemos a encontrar aquí, en las tres figuras situadas a la derecha, el pico característico del águila, la roja cabeza del buey y la testa leonina de los animales escatológicos, sino que también los otros dos justos que aparecen en la imagen exhiben grotescos rostros asnales, el uno, y un perfil de pantera, el otro. Pero también los dos músicos comparecen con cabeza animal, en particular 
el de la derecha, más visible, que toca una especie de viola con un inspirado hocico simiesco (Agamben 2005: 11-12).

La visión que se tenga de lo humano, el hecho de que lo hagamos depender de la aprehensión laboriosa de la cultura o lo pensemos predeterminado y ya resuelto por la tiranía del genoma, habrá de influir en la índole de los derechos que debería concederse a otros animales. Si lo humano es entendido como una capacidad de enculturarse, como una condición y una conquista, podemos encontrar — seguramente- animales que se muestran mucho más dotados que los simios para parecerse en ello a nosotros, aunque anatómica y genéticamente se asemejen menos a un homínido. ¿Quién estaría más de cerca de lo que son capaces de hacer los humanos, ese orangután visto por sus valedores como una suerte de grandullón discapacitado o el inteligente delfín que es capaz de aprender más de una lengua? ¿O el perro que es capaz de entender las palabras e incluso los estados de ánimo de su amo?

Los grandes simios no resultan ser las mejores mascotas posibles ni parecen muy felices de vivir con - y como- humanos. Tampoco resultan muy capaces de asumir los mínimos deberes que esos "derechos" recibidos de sus supuestos "iguales" habrían de comportar. Con todo, ha de entenderse como deseable y asumible conceder a los animales no humanos derechos a la vida, a la libertad y a no ser torturados. Pero ¿por qué no a todos? Y si no fuera así ¿a cuáles? ¿Y en razón de qué? ¿De un lejano parecido de familia o de la capacidad de comportarse como humanos? Si consideramos a lo bumano un estado al que se llega, una condición, habrá que decidirse entre dos posibles versiones de la misma. La de un modelo integrador que nos hace comprender, conocer y aprender de los otros animales o la de aquél, destructivo, que nos lleva a creernos tan superiores y singulares como para estar provistos del derecho casi divino de encerrarlos, maltratarlos y asesinarlos. ¿Cuál es la opción entre estas dos versiones o caminos que puede tomar la humanidad? Muchos estamos convencidos de que es el primero, aunque esté - también - en la cultura y condición de los humanos practicar simultáneamente las dos cosas. Porque no nos engañemos: es mucho lo que se juega en las discusiones entre "animalistas" contra "hiperhumanistas", como se llaman despectivamente entre sí los partidarios de los derechos de los animales y quienes defienden la gran diferencia de lo humano para poder convertirlos en objeto de uso o sacrificio, incluso negando que su dolor sea equiparable al nuestro. Tras la disputa elevada de los filósofos al respecto hay trifulcas menos exquisitas a pie de calle que llevan a las manos y a los juzgados, frecuentemente, a los defensores de su exterminio o su liberación.

¿Pero es la defensa parcial de un grupo de animales, mientras la de los demás quedaría estratégicamente diferida, la solución al problema? Lo que 
se discute es la concepción y la definición de lo bumano; también lo que queremos que lo bumano sea. Del hominido exterminador al hombre/mujer que, imitando y no destruyendo lo que otros animales sabían hacer mejor que ellos, llegaron a construir casas y ciudades como las abejas o las aves, a volar como éstas, a sumergirse en el mar como los peces... Ese aparente delirio de creerse capaces de hacer y ser lo que otros animales hacían y eran llevó al homínido imitador a completarse en las cualidades de los otros: a adquirir así la condición humana en lo que ésta tiene de proyecto integrador. Y fue actuando a imitación de la naturaleza que tal tipo de hombre inventó la cultura. Con él, con ese humano capaz de aprender y sentir de todos los animales y cosas, siempre hubo otros homínidos que se limitaban a destruir lo que creían poseer y que ahora adornan sus actividades aniquiladoras con la fachada civilizada del deporte o el exótico arcaísmo del ritual.

En el debate entre "animalistas" e "hiperhumanistas" al que nos referíamos en un principio, una coincidencia llama la atención y mueve a inquietud: unos y otros se acusan de convertir la ciencia en ideología y, al mismo tiempo, parecen enarbolar por separado la bandera del progresismo ideológico. Gómez Pin, en su particular alegato a favor de lo que llama "la causa del hombre", identifica dos formas o vertientes de antihumanismo contemporáneo: "La utopía de la superación del hombre por la vía de la artificialidad cibernética se hermana así con la utopía de la superación del hombre por dilución de las fronteras que lo separan del mundo animal" (Gómez Pin 2006: 14). Inteligencia reducida a la animalidad y la nueva — deshumanizada- humanidad ejemplificada por la inteligencia artificial de los robots: ésos serían en su opinión los grandes peligros. Sin embargo, hay otro antihumanismo: el que reivindica lo atávico del hombre, la necesidad del sacrificio (humano o - casi siempre - de otros animales); el que nos remite al alma, a Dios, o a la especificidad del sufrimiento de los hombres para explicar y justificar la singularidad y derechos de lo bumano, su superioridad frente a los demás seres vivos.

Pero no es exagerado suponer que, si la humanidad es un proyecto y una conquista no enteramente determinada por la naturaleza, puede producirse una deshumanización: la ya ejemplificada por los "niños salvajes". Y que los excesos de la tecnología o - mejor- la excesiva fe en ella podrían ocasionar también descarríos en el proyecto de lo humano. No todo lo que cambia al hombre es necesariamente bueno para él; no todo lo que parece transformación o progreso nos hace progresar en el camino de una positiva humanización del mundo.

$\mathrm{Y}$, en este sentido, "nada hay de sorprendente en la complicidad entre mística naturalista y tecnología contemporánea si tenemos en cuenta el irracionalismo en que se sustenta nuestra relación con esta última" (Gómez 
Pin 2006: 17). Ni tampoco parece una exageración pensar que esa homologación horizontal de lo humano con lo animal puede acarrear consecuencias jurídicas y éticas importantes (Gómez Pin 2006: 15). En ello ya se está, como hemos visto al comentar algunos de los puntos que forman parte de la Declaración del Proyecto Gran Simio. ¿A qué sirven estas tendencias, estos propósitos? ¿Se trata de elevar la dignidad de los animales o de rebajar los derechos de los humanos como recelan otros? Todo determinismo biológico resulta una ideología y, en el fondo, seguramente reaccionaria o regresiva como ya señalara Sahlins (1982: 5), pero el pretendido humanismo que sólo mira al pasado y teme al futuro quizá también lo es.

Ya señaló certeramente Lévi-Strauss respecto al evolucionismo social o cultural — tildado por él de "pseudo-evolucionismo"- que "la diferencia, olvidada con demasiada frecuencia, entre el verdadero evolucionismo y el falso evolucionismo se explica por sus fechas de aparición respectivas". Y puntualiza: "Anterior al evolucionismo biológico, teoría científica, el evolucionismo social no es, sino muy frecuentemente, más que el maquillaje falsamente científico de un viejo problema filosófico" (Lévi-Strauss 1993: 52-53).

El problema está en qué es lo que nos hace bumanos. Qué nos cambió, en apariencia, tan radicalmente. Por qué y cómo nos hemos vuelto lo que somos.

A MANERA DE CONCLUSIÓN: DEL HOMO ALALUS AL HOMO NARRANS

Gregory Bateson, que sabía tanto de antropología como de biología, solía poner un interesante ejemplo a sus alumnos:

Un hombre quería saber algo acerca del espíritu, averiguándolo no en la naturaleza, sino en su gran computadora personal. Preguntó a ésta [...]: "¿Calculas que alguna vez pensarás como un ser humano?” La máquina se puso entonces a trabajar para analizar sus propios hábitos de computación. Por último imprimió su respuesta en un trozo de papel, como suelen hacer las máquinas. El hombre corrió hacia la respuesta y halló nítidamente impresas estas palabras: ESTO ME RECUERDA UNA HISTORIA (Bateson 2006: 23).

Bateson explicaba después que "una historia es un pequeño nudo o complejo de esa especie de conectividad que llamamos relevancia". Algo que ni los animales ni las máquinas pueden producir. Sócrates, Platón o el mismo Cristo se sirvieron de historias para transmitir sus enseñanzas. Los humanos nos valemos de ellas para expresar así conocimientos que no podrían expresarse de otro modo. Y nunca sabremos bien si deberíamos de empezar a preocuparnos cuando un animal o un cyborg sean capaces de contarnos una o habríamos de preguntarnos — precisamente- por qué 
sólo nosotros parecemos capaces de hacerlo. Contarnos en historias nos hace radicalmente diferentes.

Rememorarnos mediante narraciones nos vuelve singulares. Somos humanos porque sólo nosotros nos construimos como tales narrándonos. Y es que si algo hay específico de la condición humana ello está en ser, por encima de todo, un relato en curso. Pero las historias no nos pertenecen. Ni siquiera somos los únicos seres que hemos resultado de una maraña de historias que conectan y ordenan lo que hay de relevante en los distintos episodios de la existencia. Como también dice Bateson:

El contexto y la relevancia no han de ser sólo características de la llamada "conducta" (esas historias proyectadas en la "acción"), sino también de esas historias interiores, las secuencias de la conformación de la anémona. De algún modo, la embriología de ésta debe de estar hecha de la sustancia de las historias. Y, yendo más allá, también el proceso evolutivo de millones de generaciones a través del cual la anémona (como tú y como yo) llegó a ser, también ese proceso debe estar hecho de la sustancia de las historias. Debe haber relevancia en cada eslabón de la filogenia, y entre un eslabón y el siguiente (Bateson 2006: 24).

Pero los humanos aspiramos a contar —e incluso a explicar- esas historias y las anémonas no. Ahí radica nuestra verdadera diferencia. Lo natural es que mediante una cultura adquirida (y toda cultura se adquiere) pretendamos saber de nuestras historias y de las de los otros. Sin embargo, nuestra naturaleza sólo garantiza que podemos hacerlo, no que inevitablemente lo hagamos.

Historias como la de Garín expresan, entre otras cosas, que se puede entrar y salir de la cultura o quedar al margen de ella. Garín vuelve a ser hombre no tanto porque recupera finalmente su voz gracias a que un niño recién nacido hable, lo que es científicamente imposible; sino porque cuenta su historia a los que le han apresado creyéndole un oso. Historias como la del rey egipcio indican que los experimentos para conocer lo que es natural a los humanos pueden llevar a conclusiones bastante erróneas no por el resultado del experimento en sí, sino por la interpretación que le damos. Y, aunque bastante apócrifa — como señala Kroeber (1975: 56)—, la historia contada por Herodoto sobre el rey egipcio (pero que también se ha atribuido luego a otros personajes, como el emperador mogol Akbar, el emperador Federico II Hohenstauffen o el rey Jacobo IV de Escocia), está hablando de una cierta "verdad": no hay una lengua ni cultura "naturales" de la humanidad si entendemos por natural algo que uno tiende a hacer sin aprendizaje alguno, pero lo natural es que los humanos adquieran habla y cultura y no lo contrario. Porque, en todo caso, y como apunta Agamben, el lenguaje "no es un dato natural ya ínsito en la estructura psicofísica del hom- 
bre, sino una producción histórica que, como tal, no puede ser asignada en propio ni al animal ni al hombre" (Agamben 2005: 50-51).

Los niños salvajes no son "hombres naturales", sino anomalías o —como asegurara Lévi-Strauss_ - "deformidades" de lo humano. Tampoco la naturaleza estudiada y sometida a pruebas por los hombres, los científicos, es la naturaleza en sí, sino un parte de ella aislada del resto, de su historia, de su contexto, y puesta por el científico que la examina en unas condiciones de laboratorio que la reducen a un tipo de fenómeno o de cosa, a una clase particular de anémonas, no a todas las anémonas.

Por último, los visionarios gnósticos que imaginaban el postrero banquete de los justos comiéndose, por cierto, al monstruo Leviatán con sus cabezas de animales, también estaban queriendo decir algo, una suerte de "verdad" que interpretaron de diversa manera —según Agamben recuerda (2005: 1523)_ Bataille y Kojève: como el triunfo de una reconciliación del hombre con su naturaleza animal al fin de los días, cuando termine la Historia, o como el fin de lo humano y de la Humanidad. Una y otra interpretación podrían ser válidas. Uno y otro futuro son posibles.

Del homo narrans (Niles 1999) que reinventa un viejo cuento a los cibernautas que se transmiten el último rumor en la red —en el mismo tiempo y, a veces, a unos pocos pasos unos de otros- el hombre sigue contándose historias de sí mismo y de los demás. No sabemos si los delfines se transmiten baladas - porque aún no hemos sido capaces de descifrar su canto-, pero sí que puede haber un Homero escondido en ese inmigrante que duerme en el metro y narra las historias milenarias de su tribu a quienes estén dispuestos a escucharlas. "Es a través de tales actividades mentales que las gentes han conquistado la habilidad de crearse ellas mismas como seres humanos y, por lo tanto, transformar el mundo de la naturaleza dentro de formas que no eran conocidas antes"; pues, en efecto, "sólo los seres humanos poseen ese casi increíble poder 'cosmoplástico' o habilidad de reahacer el mundo" (Niles 1999: 3). Un poder que va más allá del lenguaje, un arte de narrar y narrarse que es la base misma de la cultura y nos permite imaginar lo que hemos sido y lo que podríamos ser: nuestro futuro es como el canto del pájaro de aquel viejo cuento en que el ave era capaz de decir —según los momentos- el bien o el mal.

Al final, ciertas especulaciones paleo-antropológicas acerca del eslabón perdido y aún no encontrado entre lo animal y lo humano, o esa complacencia de la socio-biología más superficial en reconocernos como animales en nuestros primos los primates, siguen presuponiendo la existencia de un hombre-simio o, mejor, un "simio-hombre, el enfant sauvage u bomo ferus" (Agamben 2005: 52), un homo alalus u hombre-mono que no hablaba, pero 
que un buen día, dentro de un espacio de tiempo que abarca más de un millón de años, habló.

El humano, sin embargo, es humano no tanto porque habla, sino bre todo- porque cuenta y se cuenta, lo que indudablemente no podría hacer sin hablar. Y es una verdad constantemente comprobada que una generación basta para que, quienes hablan, enseñen a hablar a aquellos que por sí solos no serían capaces de hacerlo. Resulta improbable que se llegue a averiguar quién fue el primero que lo hizo, pero podemos suponer que - fuera quien fuera- estaba convencido de que tenía algo que contar: sentía ya la necesidad humana de narrarse.

Ese bominido que habló y se contó ya era bumano y antes de él no hay eslabones que encontrar, porque — sencillamente- no existía humanidad. Sólo hay una respuesta posible que podamos dar a ese "milagro" y se llama -o lo llamamos- cultura. El hombre que pintó los bisontes de Altamira con mano sabia y sorprendente perfección ya pintaba de verdad y maravillosamente, si no con la complejidad técnica de un Miguel Ángel, sí con una capacidad y sensibilidad estéticas comparables. Y, por la misma razón, el hombre que ya hablaba, probablemente desde los primeros momentos, contaba mitos sobre su pasado pre-humano: mitos que, de algún modo y como hemos visto, todavía se siguen contando. Porque los humanos se hacen con historias.

Hay una aporía o paradoja irresoluble en suponer, como el lingüista Steinthal reconocería (Cf. Agamben 2005: 51-52), que primero vino el hombre y luego el lenguaje. No hubo un homo alalus, porque tal homo no era un hombre, no era un ser que pudiera considerarse humano. La palabra es el hombre. El homo loquens es un homo narrans: para comunicarse no resulta necesario hablar, muchos animales lo hacen de distintas maneras que no incluyen el lenguaje articulado. Si se habla es para contar, para contarse, para dar cuenta del mundo y de nosotros mismos: de lo que somos y no somos. Y sólo somos humanos en la cultura. Fuera de ella la humanidad no es posible.

Como escribiría esclarecedoramente Franz Boas en lo que, sin duda, era ya un ambicioso programa científico sobre lo que la antropología había sido y - para él- debiera ser en el futuro:

Los problemas de la relación del individuo con su cultura, con la sociedad en la que vive, han recibido demasiado poca atención [...] Si alguna vez comprendemos el significado de las culturas ajenas de este modo, también seremos capaces de ver cómo muchas de nuestras líneas de conducta que creemos ancladas en lo profundo de la naturaleza humana son, de hecho, expresiones de nuestra cultura, y sujetas a modificación con el cambio cultural. No todos nuestros patrones están categorialmente determinados por nuestra condición de seres humanos, sino 
que pueden cambiar cuando las circunstancias cambian. Es nuestra tarea descubrir entre todas las variedades del comportamiento humano aquéllas que son comunes a toda la humanidad. Mediante el estudio de la universalidad y variedad de las culturas, la antropología puede ayudarnos a modelar el curso futuro de la humanidad (Boas [1932] 2008: 217).

\section{BIBLIOGRAFÍA CITADA}

Agamben, G. 2005. Lo abierto. El hombre y el animal. Valencia: Pre-textos.

Bateson, G. 2006 [1979]. Espiritu y naturaleza. Barcelona: Amorrortu Editores.

Boas, F. 1964. Cuestiones fundamentales de antropología cultural. Buenos Aires: Solar/ Hachette.

Boas, F. 2008 [1932]. Franz Boas: Textos de Antropología. Madrid: Editorial Universitaria Ramón Areces.

Francesc Díaz, A. 2008. "Introducción", en Franz Boas, Textos de Antropología: 15-38. Madrid: Editorial Universitaria Ramón Areces.

García de Diego, V. 1958. Antología de leyendas de la literatura Universal, Vol. I. Barcelona: Labor.

Gómez Pin, V. 2006. Entre lobos y autómatas. Madrid: Espasa Calpe.

Kroeber, A. L. 1975 [1917]. "Lo superorgánico", en J. S. Kahn, El concepto de cultura: textos fundamentales: 47-83. Barcelona: Editorial Anagrama.

Lévi-Strauss, Cl. 1991 [1968]. Las estructuras elementales del parentesco. Barcelona: Ediciones Paidós.

Lévi-Strauss, Cl. 1993 [1952]. Raza y cultura. Madrid: Cátedra.

Malson, L. 1973 [1964]. Los niños selváticos: mito y realidad. Madrid: Alianza.

Mosterín, J. 2006. La naturaleza humana. Madrid: Espasa Calpe.

Niles, J. D. 1999. Homo Narrans: The Poetics and Anthropology of Oral Literature. Philadelphia: University of Pennsylvania Press.

Sahlins, M. 1982. Uso y abuso de la biología. Madrid: Siglo XXI.

Fecha de recepción: 19 de noviembre de 2008

Fecha de aceptación: 15 de febrero de 2009 